\title{
A systematic review of cross-cultural adaptation of the National Institutes of Health Chronic Prostatitis Symptom Index
}

\author{
Rong-liang Dun', Jennifer Tsai ${ }^{2}$, Xiao-hua Hu' ${ }^{1}$, Jian-min Mao ${ }^{3}$, Wen-jing Zhu' ${ }^{1}$ Guang-chong Qi ${ }^{1}$ and \\ Yu Peng ${ }^{1 *}$ (D)
}

\begin{abstract}
Background: The National Institutes of Health Chronic Prostatitis Symptom Index (NIH-CPSI) was developed to accurately assess the pain, urinary symptoms, and quality of life related to chronic prostatitis/chronic pelvic pain syndrome (CP/CPPS). This study aimed to evaluate the cross-cultural adaptations of the NIH-CPSI.

Method: PubMed, Embase, CINAHL, and SciELO databases were searched from their established year to September 2020. Cross-cultural adaptations and the quality control of measurement properties of adaptations were conducted by two reviewers independently according to the Guidelines for the Process of Cross-Cultural Adaptation of Self-Report Measures and the Quality Criteria for Psychometric Properties of Health Status Questionnaire.

Results: Area total of 21 papers with 16 adaptations, and six studies of the original version of the $\mathrm{NIH}-\mathrm{CPSI}$ were enrolled in the systematic review. Back translation was the weakest process for the quality assessment of the crosscultural adaptations of the NIH-CPSI. Internal consistency was analyzed for most of the adaptations, but none of them met the standard. Only 11 adaptations reported test reliability, then only the Arabic-Egyptian, Chinese-Mainland, Danish, Italian, Persian, and Turkish adaptations met the criterion. Most adaptations reported the interpretability, but only the Danish adaptation reported the agreement. The other measurement properties, including responsiveness, and floor as well as ceiling effects were not reported in any of the adaptations.
\end{abstract}

Conclusions: The overall quality of the $\mathrm{NIH}$-CPSI cross-cultural adaptations was not organized as expected. Only the Portuguese-Brazilian, Italian, and Spanish adaptations reached over half the process for the cross-cultural adaptation. Only the Turkish adaptations finished half of the measurement properties of cross-cultural adaptations.

Keywords: Cross-cultural adaptation, Measurement property, National institutes of health chronic prostatitis symptom index, Systematic review, Translation

\section{Introduction}

Chronic prostatitis/chronic pelvic pain syndrome $(\mathrm{CP} /$ CPPS) is a common disorder among men [1]. It is defined as chronic pelvic pain not caused by other identifiable

\footnotetext{
*Correspondence: 776576020@qq.com

${ }^{1}$ Urology Surgery, Yueyang Hospital of Integrated Traditional Chinese and Western Medicine Hospital, Shanghai University of Traditional Chinese Medicine, 110 Ganhe Road, Shanghai 200437, China

Full list of author information is available at the end of the article
}

pathologies and is often characterized by with urogenital pain, lower urinary tract symptoms, psychological issues, and sexual dysfunction [2,3]. Men of all ages and races may experience prostatitis, with a worldwide prevalence of $2 \%$ to $10 \%$ [4]. The CP/CPPS causes morbidity, through both symptoms and associated impairment in health-related quality of life, thus illustrating the importance of patient-centered outcomes. Moreover, CP/CPPS is a poorly-defined clinical entity, and therefore is prone

(c) The Author(s) 2021. This article is licensed under a Creative Commons Attribution 4.0 International License, which permits use, sharing, adaptation, distribution and reproduction in any medium or format, as long as you give appropriate credit to the original author(s) and the source, provide a link to the Creative Commons licence, and indicate if changes were made. The images or other third party material in this article are included in the article's Creative Commons licence, unless indicated otherwise in a credit line to the material. If material is not included in the article's Creative Commons licence and your intended use is not permitted by statutory regulation or exceeds the permitted use, you will need to obtain permission directly from the copyright holder. To view a copy of this licence, visit http://creativecommons.org/licenses/by/4.0/. The Creative Commons Public Domain Dedication waiver (http://creativecommons.org/publicdomain/zero/1.0/) applies to the data made available in this article, unless otherwise stated in a credit line to the data. 
to misdiagnosis, mistreatment, and mismanagement [5]. The lack of a systematized and universally accepted outcome measure has led to inconsistent and vague results in CP/CPPS studies while making patient evaluation a challenge, as well as hindering research and clinical endeavors in aiding patients with CP/CPPS, thus The National Institutes of Health (NIH) Chronic Prostatitis Collaborative Research Network developed the NIH Chronic Prostatitis Symptom Index (NIH-CPSI) by Litwin and coworkers in 1999, in order to accurately assess the extent of CPPS, objectively measure the symptoms in natural history studies, and to assess the outcome parameters in clinical trials [6].

The NIH-CPSI, a self-administered questionnaire has nine items, divided into three domains: pain or discomfort (with a total score ranging from 0 to 21), urinary symptoms (with a total score ranging from 0 to 10), and impact on the quality of life (QOL) (with a total score ranging from 0 to 12 points) [6]. It is used as a diagnostic tool for the diagnosis and follow-up of CP/CPPS. In previous studies, the NIH-CPSI was shown to be reliable, valid, and responsive to change [7-10]. Pain scores of perineal or ejaculatory discomfort $\geq 8$ are good predictors of moderate to severe CP/CPPS [11]. The scale was also used by English speakers with different cultural backgrounds, such as Australian, Malaysian, and Spanish, and found to have good concurrent validity, and discriminant validity [12-14].

Initially it was written in English, but in the present day, it has been translated into many other languages including Arabic, and Chinese. Due to the cultural differences, a simple translation of the original version of a questionnaire does not guarantee similar measurement properties and rough translations may lead to construct bias, method bias, and item bias, all of which impact the validity of cross-cultural comparisons $[15,16]$. Whether the NIH-CPSI has similar reliability and validity as the logical cross-cultural adaptation of the original edition is still uncertain. Therefore, a systematic review on the quality of the cross-cultural adaptations of the NIH-CPSI is necessary.

\section{Materials and methods \\ Study selection}

The search for articles was performed in the PubMed, Embase, CINAHL and SciELO from their established year to September 2020. The search terms included "National Institutes of Health Chronic Prostatitis Symptom Index", "NIH-CPSI", "NIH Chronic Prostatitis Symptom Index", "cross-cultural", "equivalence", "translation", "validation", and "adaptation". Additional hand searching of journals, references lists, conference papers, and textbooks related to the NIH-CPSI were performed comprehensively. There was no language restriction.

\section{Inclusion and exclusion criteria}

The following studies were included:

(1) Studies related to the cross-cultural adaptation development of the NIH-CPSI;

(2) Studies reporting the process of cross-cultural adaptations;

(3) Studies on the quality assessment of at least one measurement criterion of a cross-cultural adaptation;

(4) Otherwise, other validation studies from different English-speaking societies were also included.

Emails were also sent to the authors asking for their publications that were not available in full free of charge. Studies not reporting the detailed adaptation process were excluded. Two reviewers checked the potentially relevant studies according to the inclusion and exclusion criteria, and selected eligible studies independently. Any disagreement was resolved through discussion with the third reviewer.

\section{Data extraction and quality assessment}

The language, population, publication year, and other related information about the studies were extracted by two independent reviewers in a predefined form. Then the third reviewer verified the information.

Quality assessment was made by two reviewers independently. The results were adopted on the premise that the weighted kappa ( $\mathrm{k}$ ) was more than 0.75 . Any disagreement was resolved by consensus, if a consensus could not be reached; a third reviewer decided the result.

The translation and cross-cultural adaptation methods of each study were classified according to the Guidelines for the Process of Cross-Cultural Adaptation of SelfReport Measures [17]. First, independent initial translations should be performed by a translator who is familiar with the field of medicine and by another translator with a non-medical background. These two independently performed translations ( $\mathrm{T} 1$ and $\mathrm{T} 2$ ) should be synthesized (T1-2). Next, two different translators who are native English speakers and unfamiliar with the outcome measurement tool should provide a back translation into English independently (B1 and B2). Then, the next step is an expert committee made up of methodologists, health professionals, language professionals, and translators to review the original questionnaire as well as each translation (T1, T2, T12, B1, and B2). This committee then agrees on any changes that need to adapt to the tool and creates a new draft version of the questionnaire. The 
prefinal version should then be tested with at least 30-40 patients from the target setting. This phase is important to identify the understanding, and acceptable and emotional impact of the questionnaire items, besides detecting items that were confusing or misunderstood. Finally, the final version of the questionnaire is appraised by the expert committee again, and they should unanimously approve the final version of the tool. These procedures are described with more detail in Additional file 1: Table S1.

The measurement properties were assessed according to the Quality Criteria for Psychometric Properties of Health Status Questionnaire, which focused on assessing of the psychometric properties [18]. The evaluation in this study included content validity, construct validity, internal consistency, criterion validity, concurrent validity, discriminant validity, agreement, reliability, responsiveness, and ceiling and floor effects, as well as interpretability. A clear description of measurement objectives, concept to be measured, project selection, target population participation means a positive rating for content validity. A positive rating for internal consistency was assigned when factor analysis was applied and Cronbach's $\alpha$ was found to be from 0.70 to 0.95 , with the sample size is greater than 7 *items and a minimum number of 100 subjects. Although CP is a common complaint in societies, but no golden standard exists. Therefore, all the adaptations lacked criterion validity. Reliability refers to the extent to which patients can be distinguished from each other despite measurement error (relative measurement error). Generally, an intraclass correlation coefficient (ICC) of $>0.7$ is recommended as a minimum standard for reliability [18]. These procedures are described in more detail in Additional file 2: Table S2.

\section{Results}

A total of 132 studies were identified in the initial search. Of these, 56 publications were excluded because of duplications, and 35 were not relevant. Further, 12 studies were intervention trials, and 4 were reviews. The last 25 studies were identified as potentially relevant publications after screening by titles and abstracts (Fig. 1).

Two studies were excluded due to subsequent research of the original NIH-CPSI without testing measurement properties $[19,20]$, and two studies were reviews of the NIH-CPSI [7, 21] after full-text selection. Among the 21 studies included, 16 cross-cultural adaptations of the NIH-CPSI were in 15 different languages/cultures [13, 14, 22-35]; otherwise, four studies related to the original version in the US, and one in Australia, one in Spanish, and one in Malaysian were also included [7, 9-14]. There were two adaptations in Japanese [31, 32]. Besides, two multiple were performed studies in German $(1,2)[28,29]$ (Table 1).

The sample size of the studies on validity ranged from 30 to 434, but none of them reported sample size calculation. The Original-American, Chinese-Malaysian, Japanese (a), Japanese (b) and Malaysian adaptations enrolled patients with $\mathrm{CP} / \mathrm{CPPS}$, patients with benign prostatic hyperplasia $(\mathrm{BPH})$ patients, and healthy controls $[9,13$, 31, 32]. The Arabic-Egyptian, Chinese-Mainland, Estonian, Finnish, French-Canadian, Italian, Persian, and Turkish adaptations enrolled patients with CP/CPPS, and healthy controls, but patients with BPH [22, 23, 25-27, 30, 33, 35]. The Original-American, Danish, German $(1,2)$, Portuguese-Brazilian, and Spanish adaptations included only patients with CP/CPPS $[7,11,14,24,28$, $29,34]$. More than half of the applications included consecutive patients [14, 22, 23, 26-29, 33, 34].

\section{Quality assessment of the cross-cultural adaptations of the NIH-CPSI}

The quality assessment of the adaptation process was assessed by two independent reviewers achieving a $\mathrm{K}$ of 0.876 . A consensus was achieved on $100 \%$ of occasions, when the reviewers had disagreements (Table 2).

Most adaptations reported forward translation. Only three adaptations completely met the requirement that the forward translation process should be completed by one translator with the medical background and the other one with no medical background [22, 30,34]. The two translators of the Chinese-Mainland, Estonian, Finnish, French-Canadian, Japanese (a), and Japanese (b) adaptations had a medical background and were aware of the concepts being examined in the questionnaire [23, 25-27, 31, 32]. In contrast, none of the translators of the Persian, and Spanish adaptations were familiar with the NIH-CPSI $[14,33]$. The Chinese-Malaysian, Danish, German $(1,2)$, Malaysian, and Turkish adaptations did not explain the specific background of the translators [13, 24, $28,29,35]$.

Most of the adaptations introduced the synthesis stage of translation, and met the requirements of the synthesis process.

In this review, only the Danish, Portuguese-Brazilian, and Turkish adaptations finished back translation completely [24, 34, 35]. Most of the adaptations had only one translator [13, 14, 22, 25-30, 32, 33]. Therefore, the Chinese-Mainland adaptation did not report whether the back translators were native English speakers [23], and the Japanese (a) adaptation provided no information about back translation [31].

Only the Finnish, Italian, Portuguese-Brazilian, and Spanish adaptations met the standards of composition for the existence of an expert committee [14, 26, 34]. The 


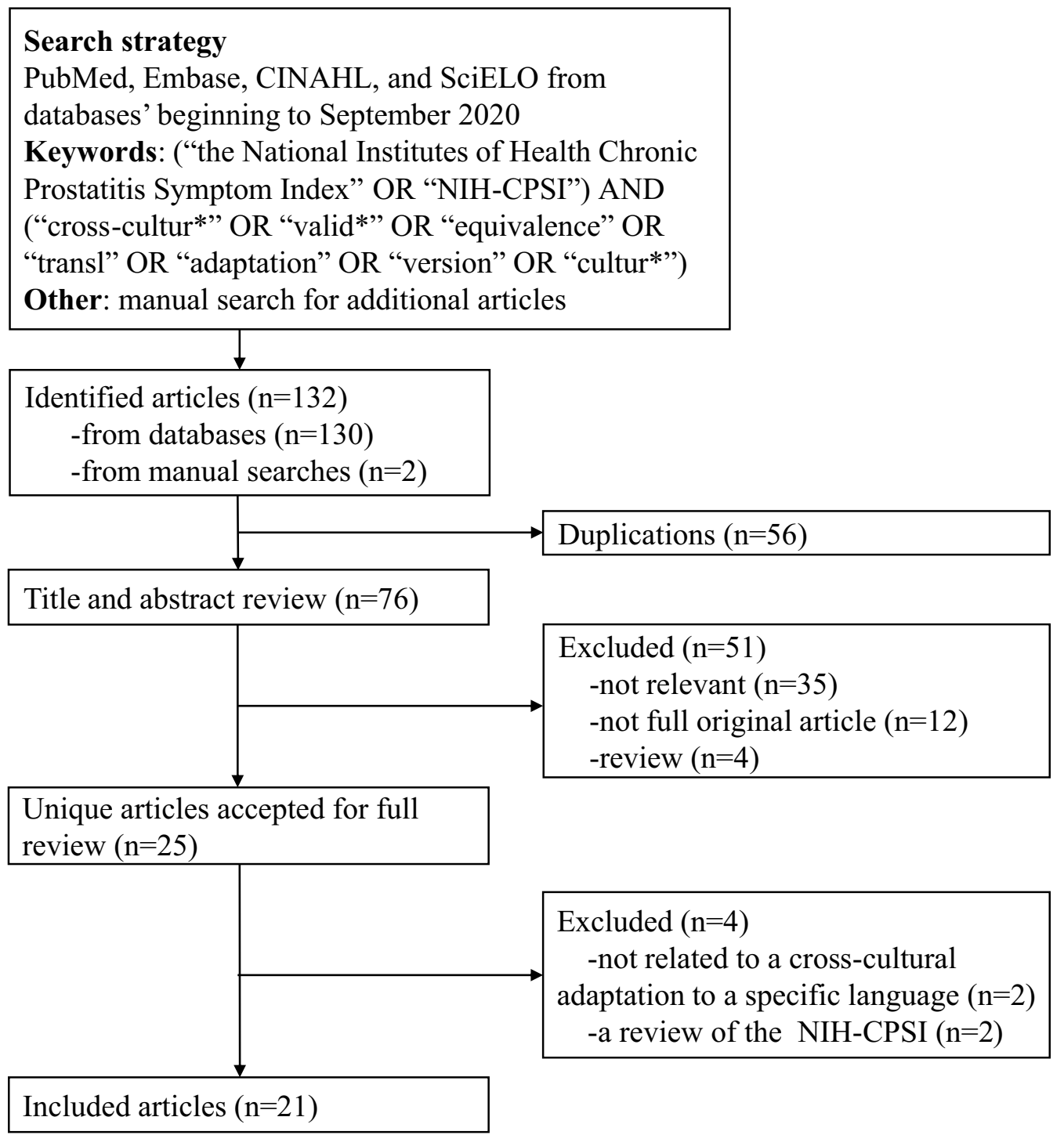

Fig. 1 Flowchart of the search process of this review

German (1,2), Persian, and Turkish adaptations did not explain the specific composition of this committee [28, 29, 33, 35]. The Arabic-Egyptian adaptation enrolled only language professionals, and the Estonian adaptation only clinicians [22, 25]; the Danish adaptation did not enroll methodologists [24]. No information was found in the other adaptations [13, 23, 27, 31, 32].

The final process of adaptation process was the pretest. Only three adaptations met the requirements [14, 25, 34]. Patients were not enough for the prefinal versions of French-Canadian, Danish, and Turkish adaptations $[24,27,35]$. The Finnish and Italian adaptations did not report the sample size of patients $[26,30]$. The others lacked information about this process $[13,22,23,28$,
29, 31-33]. All adaptations had a submission of the final version.

\section{Methodology used for property measurement}

The $\kappa$ of the two reviewers was 0.869 . The methodological quality and the measurement of the studies are provided in Table 3. All studies showed a clear description of the content validity in the development of a questionnaire.

The original version in American was found with qualified content validity, construct validity, internal consistency, test-retest reliability, responsiveness, discriminant validity, and interpretability [7,9-11]. The pain dimension of the original-American NIH-CPSI had reported ceiling effects (20.70\%) [9]. The original version in 
Table 1 Description of cross-cultural adaptations for the National Institutes of Health Chronic Prostatitis Symptom Index

\begin{tabular}{|c|c|c|c|c|c|}
\hline Language-population & Year & Sample size & Sample size calculation & Consecutive or not & $\begin{array}{l}\text { Time interval of test- } \\
\text { retest reliability }\end{array}$ \\
\hline $\begin{array}{l}\text { Original-American [7, } \\
9-11]\end{array}$ & 1999/2003/2006 & $\begin{array}{l}261 \text { CPPS/151 CP, } 149 \\
\text { BPH, } 134 \text { healthy con- } \\
\text { trols/ } 174 \text { CP/CPPS/a } \\
\text { randomly selected } \\
\text { cohort of white men } 47 \\
\text { to } 90 \text { years old }\end{array}$ & $\mathrm{No} / \mathrm{No} / \mathrm{No} / \mathrm{No}$ & No/No/No/No & 1 month/ 6 weeks \\
\hline Original-Australian [12] & 2009 & $\begin{array}{l}\text { Australian men aged } \\
\text { 16-64 years }\end{array}$ & No & No & NA \\
\hline Original-Malaysian [13] & 2006 & $\begin{array}{l}47 \mathrm{CP} / \mathrm{CPPS}, 20 \mathrm{BPH}, 13 \\
\text { healthy controls }\end{array}$ & No & No & NA \\
\hline Original-Spanish [14] & 2001 & $37 \mathrm{CP}$ & No & No & NA \\
\hline Arabic-Egyptian [22] & 2006 & $\begin{array}{l}30 \text { CPPS, } 48 \text { healthy } \\
\text { controls }\end{array}$ & No & Yes & 1 week \\
\hline Chinese-Mainland [23] & 2010 & $\begin{array}{l}162 \mathrm{CP}, 97 \text { healthy } \\
\text { controls }\end{array}$ & No & Yes & $4-6 h$ \\
\hline Chinese-Malaysian [13] & 2006 & $\begin{array}{l}32 \mathrm{CP} / \mathrm{CPPS}, 43 \mathrm{BPH}, 72 \\
\text { healthy controls }\end{array}$ & No & No & $\begin{array}{l}\text { Short-term test-retest was } \\
\text { evaluated } 1 \text { week later, } \\
\text { long-term } 14 \text { weeks later }\end{array}$ \\
\hline Danish [24] & 2019 & 112 CP/CPPS & No & No & Four days \\
\hline Estonian [25] & 2006 & $\begin{array}{l}64 \text { CP/CPPS, } 73 \text { controls } \\
\text { without CP/CPPS }\end{array}$ & No & No & NA \\
\hline Finnish [26] & 2003 & $\begin{array}{l}155 \text { CPPS, } 12 \text { controls had } \\
\text { no previous urological } \\
\text { history }\end{array}$ & No & Yes & $<1$ week later \\
\hline French-Canadian [27] & 2005 & $\begin{array}{l}36 \text { CP/CPPS, } 38 \text { controls } \\
\text { presented for pre- } \\
\text { vasectomy consultation }\end{array}$ & No & Yes & 14 days \\
\hline German $(1,2)[28,29]$ & 2001,2004 & $\begin{array}{l}137 \text { patients with CP/ } \\
\text { CPPS NIH type III }\end{array}$ & No & Yes & NA \\
\hline Italian [30] & 2005 & $\begin{array}{l}42 \text { CPPS, } 81 \text { healthy } \\
\text { controls }\end{array}$ & No & No & 1 week later \\
\hline Japanese (a) [31] & 2002 & $\begin{array}{l}34 \text { patients with CP/CPPS } \\
\mathrm{NIH} \text { type III, } 35 \mathrm{BPH}, 18 \\
\text { controls }\end{array}$ & No & No & NA \\
\hline Japanese (b) [32] & 2002 & $\begin{array}{r}103 \mathrm{CP}, 60 \mathrm{BPH}, 87 \\
\text { healthy controls }\end{array}$ & No & No & 2 weeks \\
\hline Malaysian [13] & 2006 & $\begin{array}{l}21 \mathrm{CP} / \mathrm{CPPS}, 8 \mathrm{BPH}, 12 \\
\text { healthy controls }\end{array}$ & No & No & $\begin{array}{l}\text { Short-term test-retest was } \\
\text { evaluated } 1 \text { week later, } \\
\text { long-term } 14 \text { weeks later }\end{array}$ \\
\hline Persian [33] & 2020 & $\begin{array}{l}42 \text { CP/CPPS, } 38 \text { healthy } \\
\text { controls }\end{array}$ & No & Yes & 1 week \\
\hline Portuguese-Brazilian [34] & 2013 & 30 CPPS & No & Yes & $1 \mathrm{~h}$ \\
\hline Spanish [14] & 2001 & $37 \mathrm{CP}$ & No & Yes & NA \\
\hline Turkish [35] & 2020 & $\begin{array}{l}116 \text { CP/CPPS, } 88 \text { healthy } \\
\text { controls }\end{array}$ & No & No & 2 weeks \\
\hline
\end{tabular}

$\mathrm{CP}$, chronic prostatitis; CPPS, chronic pelvic pain; $\mathrm{BPH}$, benign prostatic hyperplasia; NA= not available; German $(1,2)$, two German publications with the same adaptation; Japanese (a) and Japanese (b), two different Japanese adaptations

Australian only checked with good interpretability [12]. Original-Malaysian reported unsatisfactory internal consistency, then Original-Spanish on the contrary, since only less than 50 patients were included, the results were not convincing.

Construct validity was conducted in 10 studies, then five of them met the met the standard $[9,25,26,28,29$,
35], then Original-American, Estonian, Finnish, German $(1,2)$ versions used Pearson's $r$ correlation $[9,25,26,29]$, and Turkish versions applied Spearman's $r$ correlation [35]. A negative rating was given by the reviewer for the construct validity of Original-Spanish, French-Canadian, Japanese (a), Persian, and Spanish adaptations, because their sample sizes were smaller than 100 [14, 27, 31, 33]. 
Table 2 Quality assessment of the process for cross-cultural adaptations of the National Institutes of Health chronic prostatitis symptom

\begin{tabular}{|c|c|c|c|c|c|c|}
\hline Language-population & $\begin{array}{l}\text { Forward } \\
\text { translation }\end{array}$ & Synthesis & Back translation & $\begin{array}{l}\text { Expert committee } \\
\text { review }\end{array}$ & Pretesting & $\begin{array}{l}\text { Appraisal of } \\
\text { the Adaptation } \\
\text { Process }\end{array}$ \\
\hline Arabic-Egyptian [18] & + & + & - & - & 0 & + \\
\hline Chinese-Mainland [19] & - & + & $?$ & 0 & 0 & + \\
\hline Chinese-Malaysian [20] & $?$ & + & - & 0 & 0 & + \\
\hline Danish [21] & $?$ & + & + & - & - & + \\
\hline Estonian [22] & - & + & - & - & + & + \\
\hline Finnish [23] & - & + & - & + & $?$ & + \\
\hline French-Canadian [24] & - & + & - & 0 & - & + \\
\hline German $(1,2)[25,26]$ & $?$ & + & - & $?$ & 0 & + \\
\hline Italian [27] & + & + & - & + & $?$ & + \\
\hline Japanese (a) [28] & - & + & 0 & 0 & 0 & + \\
\hline Japanese (b) [29] & - & + & - & 0 & 0 & + \\
\hline Malaysian [20] & $?$ & + & - & 0 & 0 & + \\
\hline Persian [30] & - & + & - & $?$ & 0 & + \\
\hline Portuguese-Brazilian [31] & + & + & + & + & + & + \\
\hline Spanish [32] & - & + & - & + & + & + \\
\hline Turkish [33] & $?$ & + & + & $?$ & - & + \\
\hline
\end{tabular}

$+=$ Positive rating; $?=$ doubtful design or method; $-=$ negative rating; $0=$ no information available; German $(1,2)$, two German publications with the same adaptation; Japanese (a) and Japanese (b), two different Japanese adaptations

An analysis of the internal consistency was conducted on most of the adaptations, but only four of them met the standard $[9,25,28,29,35]$. A negative rating was given by the reviewer for the internal consistency of Arabic-Egyptian, French-Canadian, Italian, Japanese (b), PortugueseBrazilian, Malaysian, Persian, and Spanish adaptations, because their sample sizes were smaller than $100[13,14$, 22, 27, 30, 32-34]. The Chinese-Mainland, and ChineseMalaysian adaptations did not fully meet the criteria of internal consistency for the missing factor analysis [13, $23,28]$. No information was available on the internal consistency of the Finnish and Danish adaptations [24, 26]. Only half of the adaptations reported had Cronbach's $\alpha$ of more than 0.70 [14, 22, 25, 27, 32-35]. The details are shown in Table 4.

The Finnish, Italian, and Turkish adaptation showed a good correlation with the visual analogue scale or International Prostate Symptom Score, then American Urological Association symptom index a good correlation with Original-American $[9,26,30,35]$. Therefore, a positive rating for concurrent validity was given to the adaptation enrolling at least 50 patients, while the Chinese-Malaysian, French-Canadian, Japanese (a), Malaysian, and Spanish adaptations did not have 50 patients $[13,14,27,31]$. The others did not have concurrent validity.

Only two publication reported the discriminant validity following the guidelines [13]. The discriminant validity between the CP/CPPS group and each of the control groups was assessed by calculating the area under the receiver operating characteristic curve (AUC). The Original-Malaysian, Chinese-Malaysian, and Malaysian NIH-CPSI reported that the AUC of CP/ CPPS versus healthy individuals was more then 0.80 . The AUC of Original-American NIH-CPSI was 0.67, then Original-Malaysian, and Malaysian reported good discriminant validity of more than $0.75 \mathrm{CP} / \mathrm{CPPS}$ versus $\mathrm{BPH}$, except void $[11,13]$. Other studies reported only the $P$ value of difference between CPPS, and controls or BPH [13, 22, 23, 25-32, 35].

Only nine adaptations reported test reliability, but only the Original-American, Arabic-Egyptian, ChineseMainland, Danish, Italian, Persian, and Turkish adaptations met the criterion [22-24, 30, 33, 35]. The sample size for the reliability should be at least 50 patients, while the Chinese-Malaysian, French-Canadian, Japanese (b), Malaysian, and Portuguese-Brazilian adaptations enrolled less than 50 patients [13, 27, 32, 34].

Most adaptations reported the interpretability, except for Danish, Portuguese-Brazilian and Spanish adaptations $[14,24,34]$. Then, only the Danish adaptation reported the agreement [24].

Other measurements such as responsiveness, and floor and ceiling effects were not reported in any of the adaptations. 


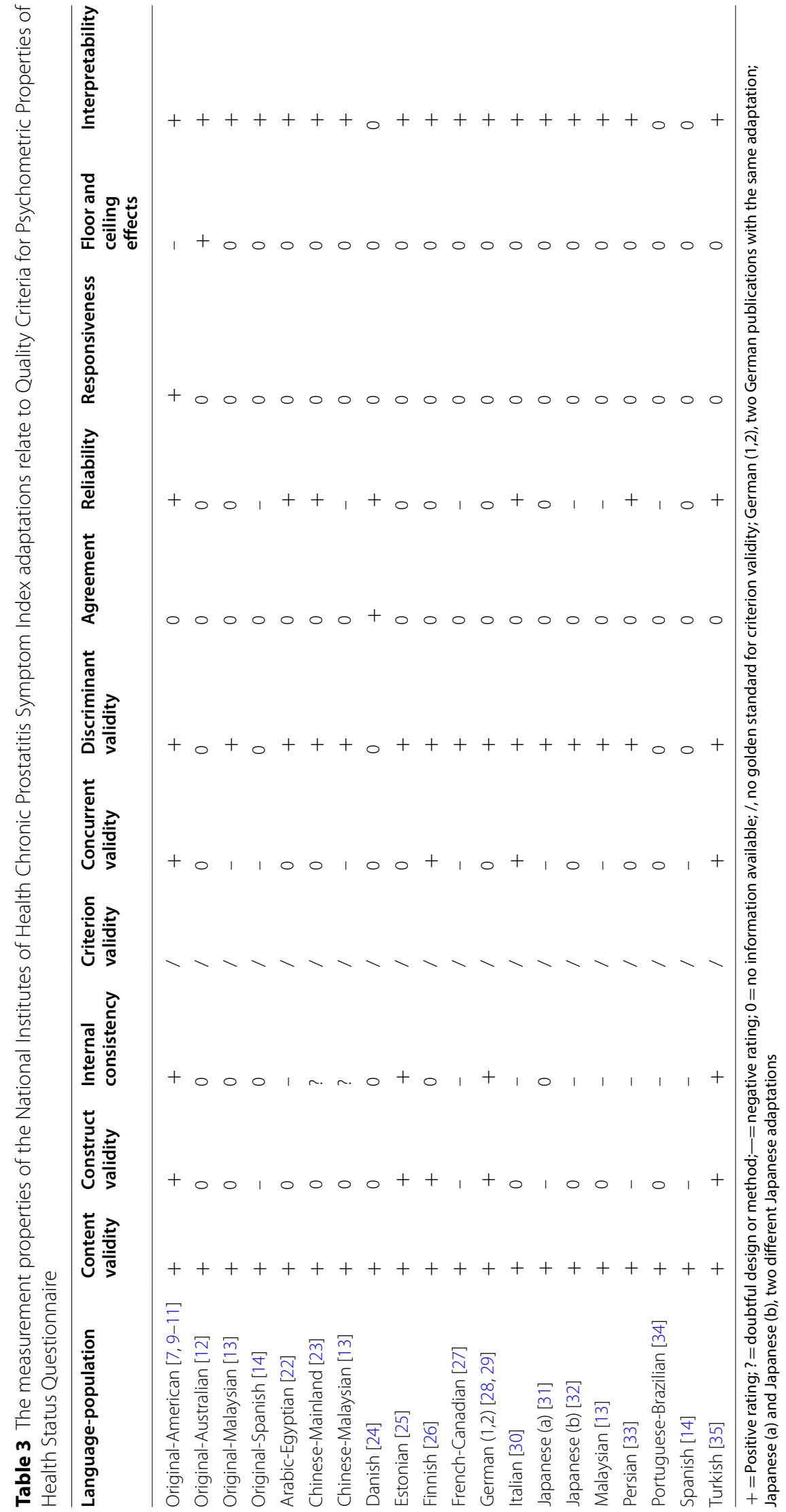




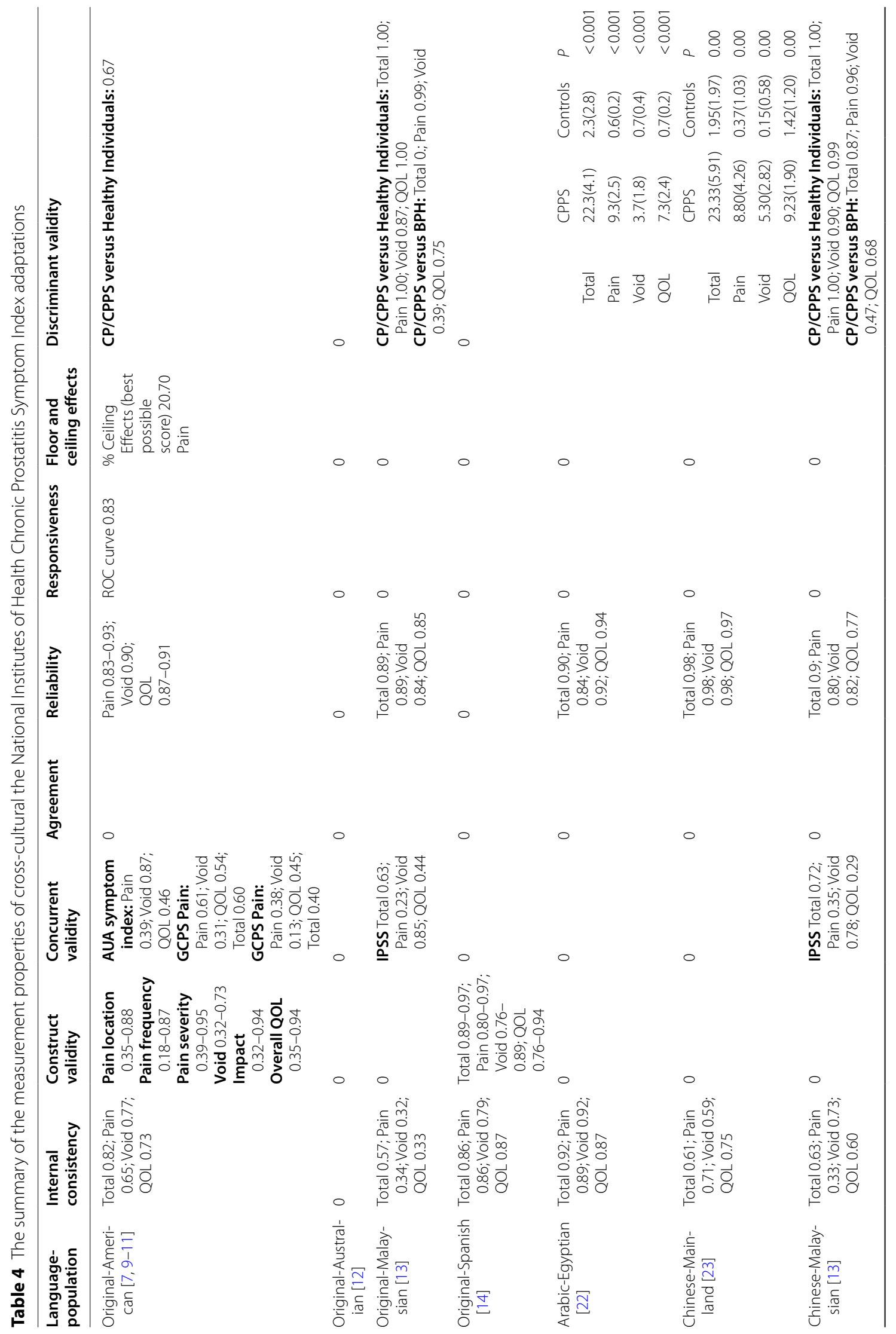




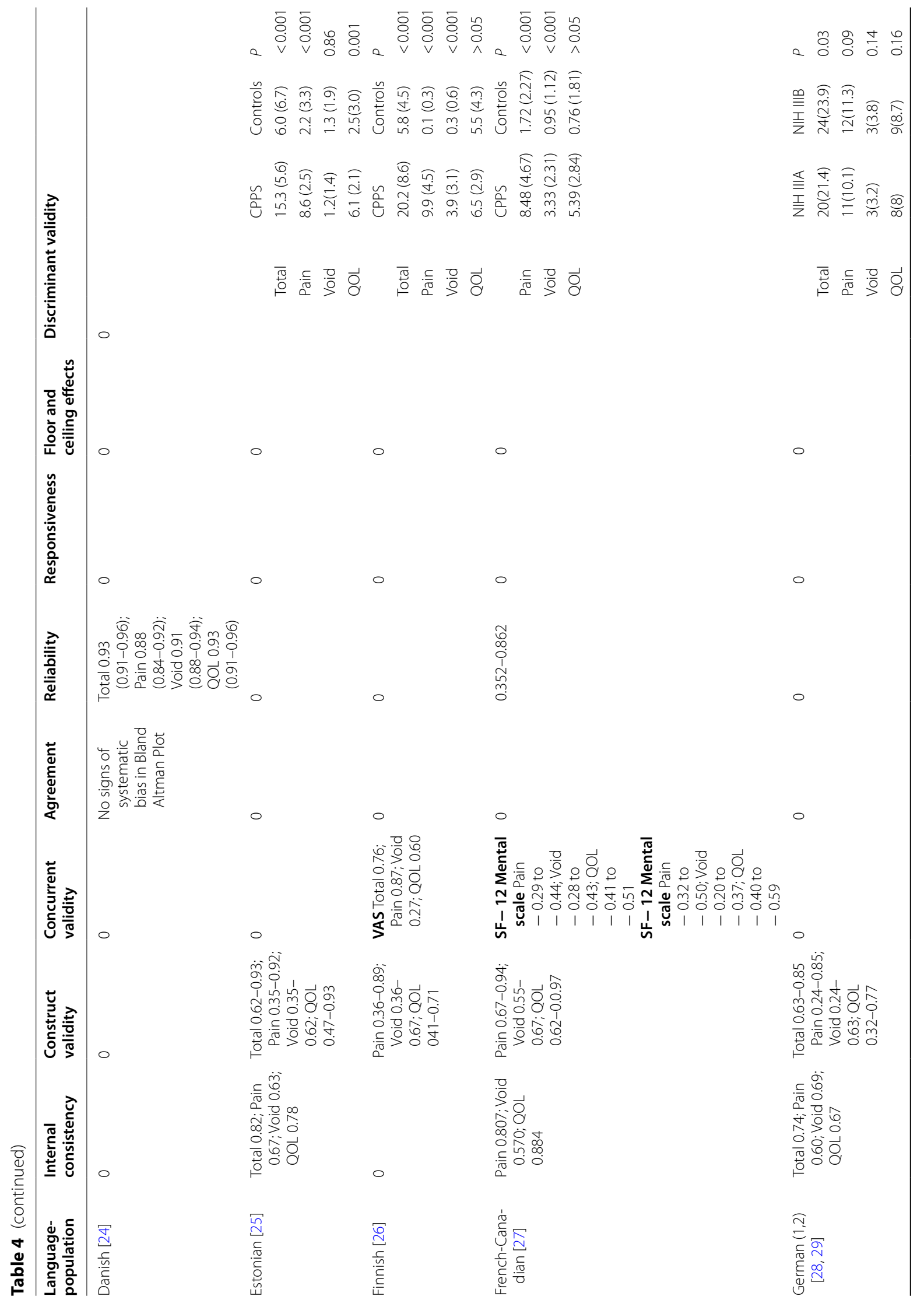




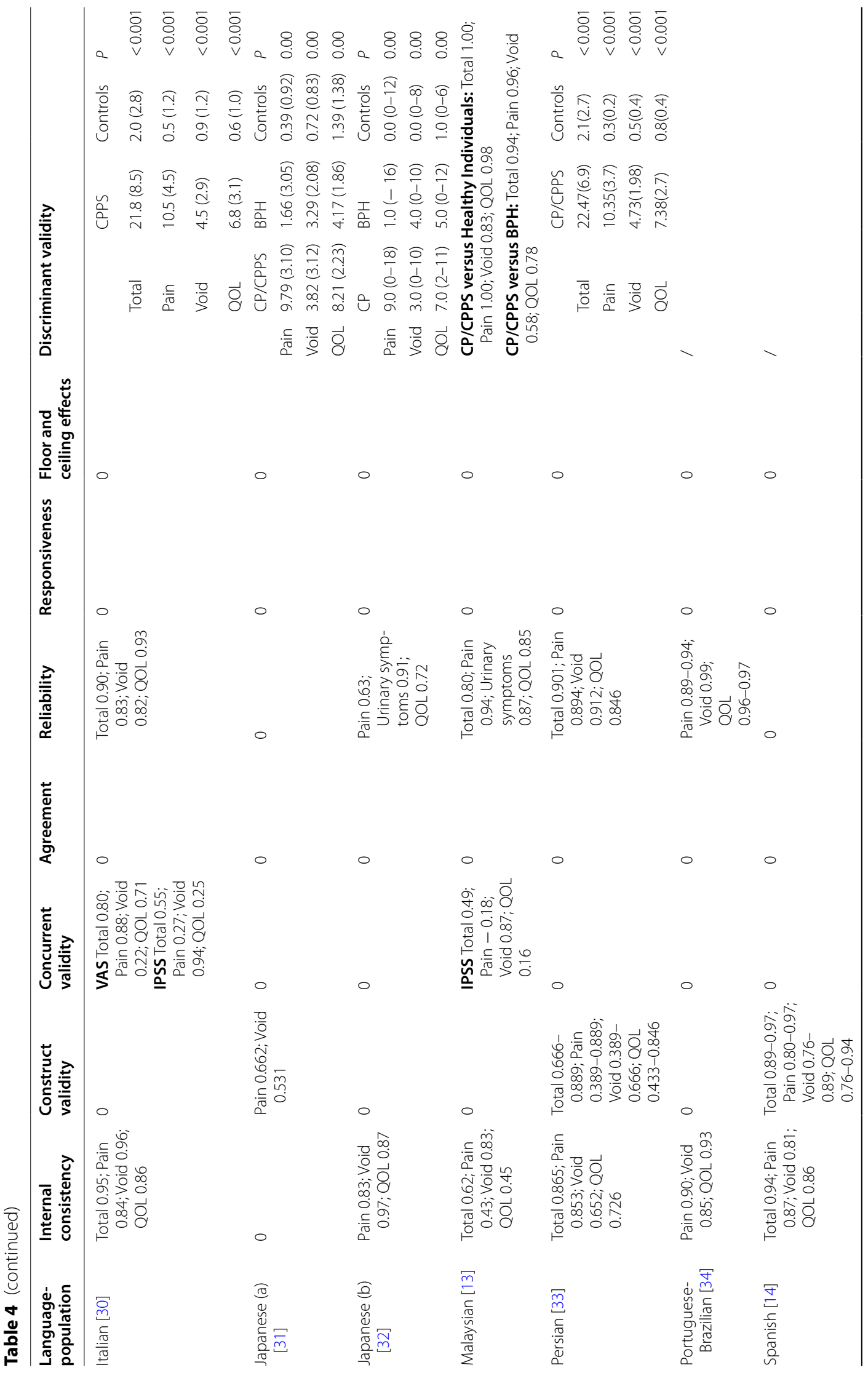




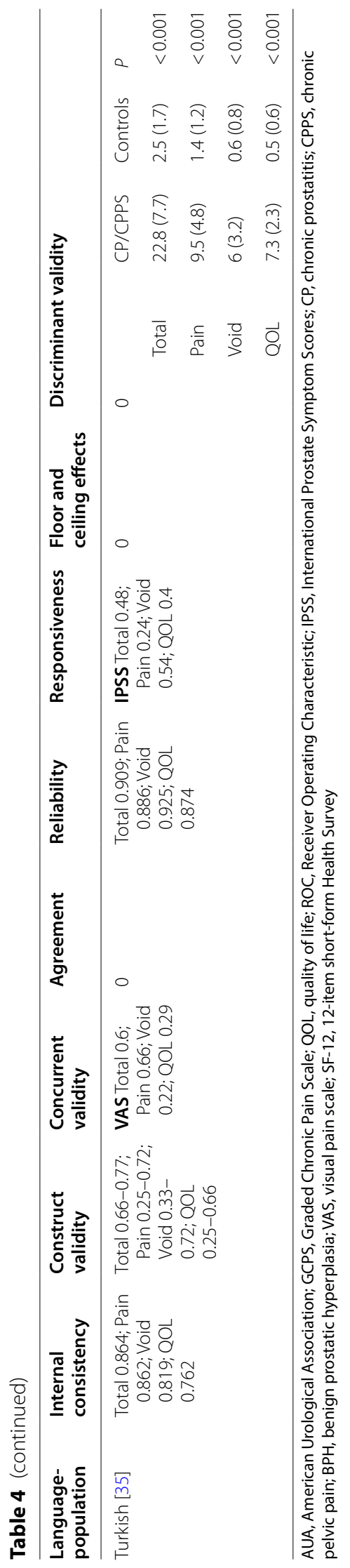




\section{Discussion}

\section{Summary of evidences}

The objective of this study was to assess the cross-cultural adaptation procedures and the measurement properties in each adaptation of the NIH-CPSI. Back translation was the weakest process for the quality assessment of the cross-cultural adaptations of the NIH-CPSI. The main reason was the presence of only one translator in most of the adaptations. An analysis of the internal consistency was conducted on most of the adaptations, but none of them met the standard. Only 11 adaptations reported test reliability, but only the Arabic-Egyptian, ChineseMainland, Danish, Italian, Persian, and Turkish adaptations met the criterion. Most adaptations reported the interpretability, but only the Danish adaptation reported the agreement. The quality of several other measurement properties, including responsiveness and internal consistency was blank.

The overall quality of the NIH-CPSI cross-cultural adaptations was unsatisfactory. Only the Italian, Portuguese-Brazilian, and Spanish adaptations provided a better quality compared with the other adaptations for the quality assessment of the cross-cultural adaptations $[14,30,34]$. Only the Turkish adaptations finished half of the measurement properties [35]. Many standards were developed to measure the cross-cultural reliability of questionnaires, such as the guidelines for the process of cross-cultural adaptation of self-reported measures in 2000 [17], Consensus-based Standards for the selection of health status Measurement Instruments (COSMIN)checklist in 2016 [36, 37], the Patient-Reported Outcomes in 2005 [38], and the Scientific Advisory Committee of the Medical Outcome Trust checklist in 1996 [39]. However, the Danish adaptation in 2019, and the Persian adaptation in 2020 showed very little improvement in the methodological quality of the cross-cultural adaptation of the NIH-CPSI [24, 33, 35].

\section{Sample size for the future cross-cultural adaptations of the NIH-CPSI}

Many adaptations did not take pretesting of the prefinal version or did not have enough patients, which was important for adaptations. Ideally, 30 to 40 participants should be included in pretesting [17]. The patients with $\mathrm{CP} / \mathrm{CPPS}$ were different from the translators, and the expert committee. Some of them did not have a high educational background, and thus the pretesting was necessary.

The sample size for the assessment of the measurement properties was also important. Additionally, 9 out of 14 adaptations reported that the internal consistency did not meet the requirement of an adequate sample size of more than 100; 5 out of 8 adaptations reported construct validity, and 5 out of 11 adaptations reported the reliability. The sample size of the studies on validity ranged from 30 to 259, but none of them reported sample size calculation. It was the most outstanding drawback for the measurement properties. Overall, 100 patients should be included in internal consistency and validity, and then 50 patients included in the reliability, agreement, and responsiveness [18]. Thus, 30 to 40 participants should be included in the pretesting process, and a sample size of at least 100 patients should be included to assess the measurement properties for NIH-CPSI.

\section{Best practice for evaluating the construct validity of the NIH-CPSI}

The construct validity of the NIH-CPSI has been tested in most of the publications, but the method is not unified. This is best estimated using the multi-trait multi-method matrix [40]. In some cases, researchers have used either latent variable modeling or Pearson product-moment correlation based on Fisher's Z transformation [41, 42]. An internally consistent scale is achieved through principal component analysis or exploratory factor analysis, followed by confirmatory factor analysis. A clear hypothesis exists that the factor structure is determined as pain or discomfort, urinary symptoms, and QOL, and hence confirmatory factor analysis (CFA) should be used [43, 44]. Robust maximum likelihood was used to estimate the CFA model. The fit of the model was assessed by combining the following fit indices: comparative fit index (CFI), Tucker-Lewis index (TLI), standardized root mean square residual (SRMR), and root mean square error of approximation (RMSEA). Pre-determined cut-off values were used to assess the fit (CFI and TLI $>0.95$ for good fit and $>0.90$ for acceptable fit; SRMR $<0.08$ for good fit and $<0.12$ for acceptable fit and RMSEA $<0.06$ for good fit and $<0.10$ for acceptable fit) [45]. It could be invalidated by too low or weak correlations with other tests, which were intended to measure the same construct. The critical values for Pearson's or Spearman's $r$ correlations were as follows: high, $r>0.50$; moderate, $0.50>r>0.30$; and low, $0.30>r>0.25$ [46]. The critical value for significant factor loading was $>0.40$ [46]. According to the guidelines, the sample size for CFA should be more than 100, and 7 times of the items [47]. The CFA was conducted using the Analysis of Moment Structures Program, or the Lavaan package in R statistical software. Then, Pearson's $r$ correlations were performed using SPSS, SAS or R statistical software.

\section{Limitations of this review}

The major English databases were included in literature retrieval. Meanwhile, manual retrieval was also shown 
in the references. Nonetheless, it could hardly guarantee that all cross-cultural adaptations of NIH-CPSI has been found. It was significant for a systematic review to assess all original studies that reported cross-cultural translations of the NIH-CPSI. Then, the systematic review design was defined before conducting the study as a priori, but this predefined systematic review protocol was not registered before.

\section{Conclusions}

The overall quality of the NIH-CPSI cross-cultural adaptations was not organized as expected. Only the Portuguese-Brazilian, Italian, and Spanish adaptations reached over half of the process for the cross-cultural adaptation. Also, only the Italian and Turkish adaptations finished half of the measurement properties of cross-cultural adaptations. Future studies should consider the sample size reasonably and test responsiveness and floor and ceiling effects. Moreover, other psychometric properties should follow the guidelines.

\section{What is new?}

1. The overall quality of the NIH-CPSI cross-cultural adaptations is not organized as expected.

2. Only the Portuguese-Brazilian and Spanish adaptations showed a better quality than the other adaptations for the quality assessment.

3. For the measurement properties, only the Italian, and Turkish adaptations finished half of the measurement properties.

4. Many standards had been developed to measure the cross-cultural reliability of questionnaires, however, from the Danish adaptation in 2019, and Persian adaptation in 2020, we could find that there was very little improvement in the cross-cultural adaptation of $\mathrm{NIH}-\mathrm{CPSI}$.

\section{Supplementary Information}

The online version contains supplementary material available at https://doi. org/10.1186/s12955-021-01796-8.

Additional file 1: Table S1. Guidelines for the Process of Cross-Cultural Adaptation of Self-Report Measures

Additional file 2: Table S2. Quality Criteria for Psychometric Properties of Health Status Questionnaire

\section{Authors' contributions}

The study was conceived by RLD, GCQ, and YP. RLD, JT, XHH, JMM,WJZ developed the eligibility criteria, search strategy, risk of bias assessment strategy and data extraction plan with guidance from GCQ, and YP. RLD wrote the manuscript. All authors read and approved the final manuscript.
Funding

Shanghai Key TCM specialty training program (urology specialty); NSFC funded program (81904070).

\section{Availability of data and materials}

The datasets used and/or analysed during the current study are available from the corresponding author on reasonable request.

\section{Declarations}

Ethics approval and consent to participate

Ethics approval and consent to participate is not applicable.

Consent for publication

All authors have agreed to publish this study.

\section{Competing interests}

The authors declare that they have no competing interests.

\section{Author details}

${ }^{1}$ Urology Surgery, Yueyang Hospital of Integrated Traditional Chinese and Western Medicine Hospital, Shanghai University of Traditional Chinese Medicine, 110 Ganhe Road, Shanghai 200437, China. ${ }^{2}$ Karolinska Institute, Stockholm, Sweden. ${ }^{3}$ Urology Surgery, Shanghai Seventh People's Hospital, Shanghai, China.

Received: 9 December 2020 Accepted: 24 May 2021

Published online: 31 May 2021

\section{References}

1. Krieger JN, Lee SW, Jeon J, Cheah PY, Liong ML, Riley DE. Epidemiology of prostatitis. Int J Antimicrob Agents. 2008;31(Suppl 1):S85-90.

2. Rees J, Abrahams M, Doble A, Cooper A. Diagnosis and treatment of chronic bacterial prostatitis and chronic prostatitis/chronic pelvic pain syndrome: a consensus guideline. BJU Int. 2015;116(4):509-25.

3. Polackwich AS, Shoskes DA. Chronic prostatitis/chronic pelvic pain syndrome: a review of evaluation and therapy. Prostate Cancer Prostatic Dis. 2016;19(2):132-8.

4. Bajpayee P, Kumar K, Sharma S, Maurya N, Kumar P, Singh R, Lal C. Prostatitis: prevalence, health impact and quality improvement strategies. Acta Pol Pharm. 2012;69(4):571-9.

5. Rayegani SM, Razzaghi MR, Raeissadat SA, Allameh F, Eliaspour D, Abedi AR, Javadi A, Rahavian AH. Extracorporeal shockwave therapy combined with drug therapy in chronic pelvic pain syndrome - a randomized clinical trial. Urol J. 2019;17(2):185-91.

6. Litwin MS, McNaughton-Collins M, Fowler FJ Jr, Nickel JC, Calhoun EA, Pontari MA, Alexander RB, Farrar JT, O'Leary MP. The National Institutes of Health chronic prostatitis symptom index: development and validation of a new outcome measure. Chronic Prostatitis Collaborative Research Network. J Urol. 1999;162:369-75.

7. Litwin MS. A review of the development and validation of the National Institutes of Health Chronic Prostatitis Symptom Index. Urology. 2002;60:14-8 (discussion 8-9).

8. Magri V, Wagenlehner FM, Marras E, Van Till JW, Houbiers J, Panagopoulos P. Petrikkos GL, Perletti G. Influence of infection on the distribution patterns of $\mathrm{NIH}-$ Chronic Prostatitis Symptom Index scores in patients with chronic prostatitis/chronic pelvic pain syndrome (CP/CPPS). Exp Ther Med. 2013;6(2):503-8.

9. Propert KJ, Litwin MS, Wang Y, Alexander RB, Calhoun E, Nickel JC, O'Leary MP, Pontari M, McNaughton-Collins M, Chronic Prostatitis Collaborative Research Network (CPCRN). Responsiveness of the National Institutes of Health Chronic Prostatitis Symptom Index (NIH-CPSI). Qual Life Res. 2006;15(2):299-305.

10. Turner JA, Ciol MA, Von Korff M, Berger R. Validity and responsiveness of the national institutes of health chronic prostatitis symptom index. J Urol. 2003;169(2):580-3.

11. Roberts RO, Jacobson DJ, Girman CJ, Rhodes T, Lieber MM, Jacobsen SJ. Low agreement between previous physician diagnosed prostatitis 
and national institutes of health chronic prostatitis symptom index pain measures. J Urol. 2004;171(1):279-83.

12. Ferris JA, Pitts MK, Richters J, Simpson JM, Shelley JM, Smith AM. National prevalence of urogenital pain and prostatitis-like symptoms in Australian men using the National Institutes of Health Chronic Prostatitis Symptoms Index. BJU Int. 2010;105(3):373-9.

13. Cheah PY, Liong ML, Yuen KH, Lee S, Yang JR, Teh CL, Khor T, Yap HW, Krieger JN. Reliability and validity of the National Institutes of Health: Chronic Prostatitis Symptom Index in a Malaysian population. World J Urol. 2006;24(1):79-87.

14. Collins MM, O'Leary MP, Calhoun EA, Pontari MA, Adler A, Eremenco S, Chang CH, Odom L, Litwin MS. The Spanish National Institutes of HealthChronic Prostatitis Symptom Index: translation and linguistic validation. J Urol. 2001;166(5):1800-3.

15. Yao M, Xu BP, Tian ZR, Ye J, Zhang Y, Wang YJ, Cui XJ. Cross-cultural adaptation of the Neck Pain and Disability Scale: a methodological systematic review. Spine J. 2019;19(6):1057-66.

16. Van VFJR, Poortinga YH. Towards an integrated analysis of bias in crosscultural assessment. Eur J Psych Asses. 1997;13(1):21-9.

17. Beaton DE, Bombardier C, Guillemin F, Ferraz MB. Guidelines for the process of cross-cultural adaptation of self-report measures. Spine (Phila Pa 1976). 2000;25(24):3186-91.

18. Terwee $C B$, Bot SD, de Boer MR, van der Windt DA, Knol DL, Dekker J, Bouter LM, de Vet HC. Quality criteria were proposed for measurement properties of health status questionnaires. J Clin Epidemiol. 2007;60(1):34-42.

19. Wagenlehner FM, van Till JW, Magri V, Perletti G, Houbiers JG, Weidner W, Nickel JC. National Institutes of Health Chronic Prostatitis Symptom Index (NIH-CPSI) symptom evaluation in multinational cohorts of patients with chronic prostatitis/chronic pelvic pain syndrome. Eur Urol. 2013:63(5):953-9.

20. Schneider H, Ludwig M, Weidner W, Brahler E. Experience with different questionnaires in the management of patients with CP/CPPS: GPSS, IPSS and $\mathrm{NIH-CPSI}$. World J Urol. 2003;21 (3):116-8 (discussion 115).

21. Clemens JQ, Calhoun EA, Litwin MS, McNaughton-Collins M, Dunn RL, Crowley EM, Landis JR. Rescoring the NIH chronic prostatitis symptom index: nothing new. Prostate Cancer Prostatic Dis. 2009;12(3):285-7.

22. El-Nashaar A, Fathy A, Zeedan A, Al-Ahwany A, Shamloul R. Validity and reliability of the Arabic version of the National Institutes of Health Chronic Prostatitis Symptom Index. Urol Int. 2006;77(3):227-31.

23. Li YFXH, Yang Y, Cai Y, Yang YR. Evaluation of a modified Chinese version of the National Institutes of Health-Chronic Prostatitis Symptom Index. Chin J Uro. 2010;31:5

24. Kildegaard D, Graugaard-Jensen C, Andersen K. Danish version of the National Institutes of Health-Chronic Prostatitis Symptom Index $(\mathrm{NIH}-$ (PSI) questionnaire: a linguistic translation, cross-cultural adaptation and test-re-test reliability study. Scand J Urol. 2019;53(1):62-8.

25. Korrovits P, Punab M, Mehik A, Mandar R. The Estonian version of the National Institutes of Health chronic prostatitis symptom index. Andrologia. 2006;38(3):106-9.

26. Leskinen MJ, Mehik A, Sarpola A, Tammela TL, Jarvelin MR. The Finnish version of The National Institutes of Health Chronic Prostatitis Symptom Index correlates well with the visual pain scale: translation and results of a modified linguistic validation study. BJU Int. 2003;92(3):251-6.

27. Karakiewicz PI, Perrotte P, Valiquette L, Benard F, McCormack M, Menard C, McNaughton Collins M, Nickel JC. French-Canadian linguistic validation of the NIH Chronic Prostatitis Symptom Index. Can J Urol. 2005;12(5):2816-23.

28. Hochreiter W, Ludwig M, Weidner W, Wagenlehner F, Naber K, Eremenco $\mathrm{S}$, Arnold B. National Institutes of Health (NIH) Chronic Prostatitis Symptom Index. The German version. Der Urologe Ausg A. 2001;40(1):16-7.

29. Schneider H, Brahler E, Ludwig M, Hochreiter W, Collins MF, Eremenco S, Weidner W. Two-year experience with the German-translated version of the NIH-CPSI in patients with CP/CPPS. Urology. 2004;63(6):1027-30.
30. Giubilei G, Mondaini N, Crisci A, Raugei A, Lombardi G, Travaglini F, De Popolo G, Bartoletti R. The Italian version of the National Institutes of Health Chronic Prostatitis Symptom Index. Eur Urol. 2005;47(6):805-11.

31. Monden K, Tsugawa M, Ninomiya Y, Ando E, Kumon H. A Japanese version of the National Institutes of Health Chronic Prostatitis Symptom Index (NIH-CPSI, Okayama version) and the clinical evaluation of cernitin pollen extract for chronic non-bacterial prostatitis. Nihon Hinyokika Gakkai Zasshi. 2002;93(4):539-47.

32. Kunishima Y, Matsukawa M, Takahashi S, Itoh N, Hirose T, Furuya S, Takatsuka K, Mori M, Tsukamoto T. National institutes of Health Chronic Prostatitis Symptom Index for Japanese men. Urology. 2002;60(1):74-7.

33. Allameh F, Mansouri Tehrani MM, Tasharrofi MA, Ganji Jameshouran MA. Validation of the Persian Version of the National Institute of Health Chronic Prostatitis Symptom Index. Urol J. 2020;18(01):117-21.

34. Novotny C, Deves E, Novotny R, Rodrigues IK, Neves FS. Cultural adaptation of the National Institutes of Health—chronic prostatitis symptom index (NIH-CPSI)—-to Brazilian spoken Portuguese: NIH-CPSI (Braz). Int Braz J Urol. 2013;39(5):683-91.

35. Coşkun A, Can U, Tarhan F, KavukoĞlu Ö, Narter KF. Reliability and validity of the national institute of Health Chronic Prostatitis Symptom Index questionnaire in Turkish Population. Turk J Med Sci. 2020;51 (2):501-7.

36. Mokkink LB, Prinsen CA, Bouter LM, Vet HC, Terwee CB. The COnsensusbased Standards for the selection of health Measurement INstruments (COSMIN) and how to select an outcome measurement instrument. Braz J Phys Ther. 2016;20(2):105-13.

37. Prinsen CAC, Mokkink LB. COSMIN guideline for systematic reviews of patient-reported outcome measures. Qual Life Res. 2018;27(5):1147-57.

38. Wild D, Grove A, Martin M, Eremenco S, McElroy S, Verjee-Lorenz A, Erikson P. Principles of Good Practice for the Translation and Cultural Adaptation Process for Patient-Reported Outcomes (PRO) Measures: report of the ISPOR Task Force for Translation and Cultural Adaptation. Value Health. 2005;8(2):94-104.

39. Lohr KN, Aaronson NK, Alonso J, Burnam MA, Patrick DL, Perrin EB, Roberts JS. Evaluating quality-of-life and health status instruments: development of scientific review criteria. Clin Ther. 1996;18(5):979-92.

40. Raykov T, Marcoulides GA. Introduction to psychometric theory. New York, NY: Taylor \& Francis Group; 2011.

41. Churchill GA. A paradigm for developing better measures of marketing constructs. J Mark Res. 1979;16:64-73.

42. de Vet HCW, Ader HJ, Terwee CB, Pouwer F. Are factor analytical techniques appropriately used in the validation of health status questionnaires? A systematic review on the quality of factor analyses of the SF-36. Qual Life Res. 2005;14:1203e18.

43. Boateng GO, Neilands TB, Frongillo EA, Melgar-Quiñonez HR, Young SL. Best practices for developing and validating scales for health, social, and behavioral research: a primer. Front Public Health. 2018;1 1(6):149.

44. Campbell DT, Fiske DW. Convergent and discriminant validity by the multitrait-multi method matrix. Psychol Bull. 1959;56:81-105.

45. Hatcher L. A step-by-step approach to using the SAS system for factor analysis and structural equation modeling. Cary, NC: SAS Institute Inc.; 1994.

46. Cohen J. Statistical power analysis for the behavioral sciences. Hillsdale, NJ: Erlbaum; 1988

47. Kline P. The handbook of psychological testing. London: Routledge; 1993.

\section{Publisher's Note}

Springer Nature remains neutral with regard to jurisdictional claims in published maps and institutional affiliations. 